\title{
Evaluation of the World Breastfeeding Trend Initiative Reports of the Countries Affiliated to the Turkish Cooperation and Coordination Agency
}

\author{
Iş1lay Gedik Tekinemre ${ }^{1}$, Burcu Kayhan Tetik ${ }^{2}$ \\ ${ }^{1}$ Elazig Provincial Health Directorate, Elazig, Turkey \\ ${ }^{2}$ Inonu University Medical School, Department of Family Medicine, Malatya Turkey \\ Received: 20 March 2019, Accepted: 06 April 2020, Published online: 30 April 2020 \\ (C) Ordu University Institute of Health Sciences, Turkey, 2020
}

\begin{abstract}
Breastfeeding has many benefits for the physical and psychological development of the baby and its positive effects continue for life. Breastfeeding correctly and properly whenever the baby wants, except in compulsory situations feeding only with breast milk during the first six months and breastfeeding is recommended in addition to supplementary food for at least two years of age. In most parts of the world, programs to encourage breastfeeding are implemented. In this study, the rates of countries that sent reports to World Breastfeeding Trend Initiavite (WBTI) from countries that are members of the Turkish Cooperation and Coordination Agency (TCCA) Presidency on breastfeeding and bottle use. It was observed that the rates were below the standards in the specified reports. Increasing breastfeeding rates, reduce baby bottle use and thus, it is thought that educational programs should be focused on in order to raise healthier generations.
\end{abstract}

Key words: Breastfeeding, Turkish Cooperation and Coordination Agency, World Breastfeeding Trend Initiative

Suggested Citation: Gedik Tekinemre, Kayhan Tetik B. Evaluation of the World Breastfeeding Trend Initiative Reports of the Countries Affiliated to the Turkish Cooperation and Coordination Agency. Middle Black Sea Journal of Health Science, 2020; 6(1):139-143.

\section{Address for correspondence/reprints:}

Burcu Kayhan Tetik

Telephone number: +90 (505) 6212444

ORCID-ID 0002-0000-3976-4986

E-mail: drburcukayhan@hotmail.com

DOI: $10.19127 / \mathrm{mbsjohs.706513}$

\section{Introduction}

Breast milk is very important in the first 2 years of a baby's life because it has the ideal content to meet the needs of the baby. An examination of the data on the importance of childhood nutrition reveals that about 1.5 million children die due to acute nutritional deficiency per year (Lancet, 2000). Although breastfeeding precisely prevents infant mortality, the rate of breastfeeding in Japan for the first 6 months is $3 \%$; this rate is $47.2 \%$ in USA and in our country $41 \%$ (Liu, 2013; Centers for Disease Control and Prevention. Breastfeeding report card United States, 2012; Turkey Demographic and Health Survey, 2018). Assembly, it has been declared as one of the six global targets to increase the rate of exclusive breastfeeding in the first six months up to at least 50\% by year 2025 (World Health Organization, 2014). 
Breastfeeding is a unique feeding method for the healthy growth and development of the baby (Akyuz, 2007). It is very important to feed the baby only with breast milk for the first six months after birth and to continue breastfeeding with appropriate supplementary foods, until at least two years of age (World Health Organization, 2020). Breast milk contains most of the vitamins at the desired level, except vitamin $\mathrm{D}$ and $\mathrm{K}$. Besides being abundantly rich in nutrient content, breast milk plays an important role in the development of the baby and augmenting immunity, due to the growth factors and immunological factors it contained. Breast milk is easy to digest and protects the baby from gastrointestinal problems; it also provides protection against the development of type 2 diabetes mellitus and obesity. Being rich in essential fatty acids, it supports brain and nerve tissue development. Breastfeeding also protects the mother against diseases such as breast cancer, ovarian cancer, and osteoporosis. In addition, it strengthens the emotional bond between the mother and the baby (Samur, 2008). Mothers should be educated and encouraged for breastfeeding, because breast milk is very important for the health of the baby and the mother. A successful breastfeeding during the first 6 months depends on several factors including the mother's thoughts about breastfeeding, the health condition of the baby and the mother, the feeding of the baby in the first days after birth, the nutrition of the mother during the lactation period, and prenatal and postnatal interventions of midwives and nurses to provide lactation. The long-term success of breastfeeding depends on factors including the time of starting breastfeeding, the frequency of breastfeeding, the time to switch to supplementary food, and the mother's working conditions (Hoyer, 1998; Schmied, 1999; Chierici, 1999; Raister, 2000; Akyuz, 2007).

\section{Breastfeeding in Turkey}

WHO and UNICEF recommend breast-feeding babies exclusively for the first six months and continuing breast-feeding with adequate complementary food for up to two years of age (Gartner, 2005). The same recommendation is accepted by Ministry of Health, in our country. Training of breastfeeding, beginning especially after the $32^{\text {th }}$ week of pregnancy, has been proven to increase the duration of breastfeeding, in many studies (Betrini, 2003).

Breastfeeding has been supported by "Monitoring the Growth Program", since 1987, and by the implementation of "Breast Milk Promotion and Baby-Friendly Health Institutions Program", since 1991,with the cooperation of UNICEF (Bolat, 2011).Ten steps of successful breastfeeding have been introduced to all health institutions by the Ministry of Health. A health institution that carries out these steps is entitled as a baby-friendly health institution. Correct practices required for nutrition during infancy and early childhood include starting breastfeeding within the first hour of life, breastfeeding for the first six months of life, exclusively, continuing breastfeeding for two years or more, and introducing safe, convenient and adequate supplementary foods at 6 months of age (Turkey Demographic and Health Survey, 2018). Breastfeeding in the first hour after the delivery is very important for the establishment of the bond between the mother and the baby and providing the baby with colostrum, which is very beneficial and protective for the baby. According to Turkey Demographic and Health Survey (TDHS) 2018 report, the rate of starting breastfeeding within the first hour was $71 \%$, the rate of feeding with only breast milk for the first 6 months was $41 \%$, and median duration of breastfeeding was 16.7 months. Although bottle feeding is not recommended in the first 2 years of age, the frequency of use is high in our country. According to the data of TDHS 2018 report, the rate of feeding with a bottle was 53\% in the first 2 years (Turkey Demographic and Health Survey, 2018).

\section{Turkish Cooperation and Coordination Agency}

Turkish Cooperation and Coordination Agency (TCCA) was established within the Ministry of Culture and Tourism of the Republic of Turkey, in 1992, in order to implement and coordinate the aid, projects and collaboration efforts to our consanguine living in newly established countries in Central Asia. TCCA has been an instrument to implement our foreign policy in many regions and countries. While the initial aim of the institution was to help Turkic Republics to produce their own social structure, to develop their identity, cultural and political rights, to improve their technical infrastructure, it continued to provide help in several fields including education, health, restoration, agricultural development, finance, tourism, industry, etc. (Turkish Cooperation and Coordination Agency, 2020).

\section{World Breastfeeding Trend Initiavite}

The Breastfeeding Promotion Network of India (BPNI) has been serving as a breastfeeding incentive network of India for 28 years. Its main purpose is to help all countries around the world to produce 
policies on baby nutrition. BPNI is also the global secretary of the World Breastfeeding Trend Initiative (WBTI) program. WBTI was first established, in 2004, as an assessment and comparison tool of the policies and programs of the World Health Organization for the implementation of the global strategy for nutrition of infants and children, on the basis of countries. WBTI does this through a 15-step strategy including,

1. National Policy,

2. Management and Financing,

3. Baby-Friendly Hospital İnitiative / Ten Steps to Successful Breastfeeding,

4. Implementing Baby Food Codex,

5. Maintaining Delivery,

6. Health and Nutrition Care Systems,

7. Guidance Services for Breastfeeding Mothers and Pregnant Women,

8. HIV and İnfant Nutrition,

9. Nutrition of Babies and Young Children İn Emergency Conditions,

10. Monitoring and Evaluation,

11. İnitiating Breastfeeding Within the First Hour of Delivery,

12. Exclusive Breastfeeding for The First Six Months,

13. Median Breastfeeding Time,

14. Bottle Feeding,

15. Complementary Feeding-İntroduction Of Solid, Semi-Solid or Soft Foods.

Countries agreeing to participate in this program write their reports according to this 15-step strategy and send these reports to WBTI for evaluation (World Breastfeeding Trends Initiative, 2020). WBTI reviews the reports, records the weaknesses and strengths of the countries in a separate report and keeps these reports (World Breastfeeding Trends Initiative, 2020). Turkey WBTI report of the Ministry of Health was presented in 2015 with the support of universities and non-governmental organizations (World Breastfeeding Trends Initiative, 2020). Turkey has taken 80 points out of 100 by the report evaluated WBTI (World Breastfeeding Trends Initiative, 2020).

The aim of this article is to review the reports gathered from WBTI about the TIKA member countries who provided information to them and provide information regarding the amount of breastfeeding in these countries. The countries who did not provide information to WBTI have been excluded from the review.
Republic of South Africa submitted its' report to WBTI, in 2010. According to this report, breastfeeding rate was $12 \%$ for the first 3 months, and the rate of exclusive breastfeeding for the first 4-6 months was $1.5 \%$. It was reported that $46 \%$ of the babies started bottle feeding, in the first 10 weeks (World Breastfeeding Trends Initiative, 2020). When we examined the reports submitted to WBTI, by Mozambique, Kenya, and Afghanistan, in 2012, the rate of starting breastfeeding in the first 1 hour in was $63 \%$ Mozambique, rate of exclusive breastfeeding for the first 6 months was 37\%, and the median duration of breastfeeding was 18 months. Starting bottle feeding rate was $30 \%$ for the first 6 months, whereas it was observed that the baby-friendly hospital application was not available in the country. In the report submitted by Kenya, the rate of breastfeeding in the first 1 hour was $58 \%$, the rate of exclusive breastfeeding in the first 6 months was $31.9 \%$, and the median duration of breastfeeding was 20 months. According to the report submitted by Afghanistan, the rate of exclusive breastfeeding for the first 6 months was $54 \%$, the median breastfeeding period was 23 months, and the rate of bottle usage was $28 \%$. Breastfeeding rates were found to be lower in girls. Although, baby-friendly hospital practice was available in the country, sustainability problems were present, due to cultural and traditional obstacles (World Breastfeeding Trends Initiative, 2020). Ethiopia submitted its' report to WBTI, in 2013. The report revealed that $56 \%$ of the deliveries took place at home, the rate of exclusive breastfeeding in the first 6 months was only $31.9 \%$, and the median breastfeeding period was 20 months. Although 10 steps of successful breastfeeding have been applied as a part of baby-friendly hospital initiative, we observed that the rate of baby-friendly hospitals was only 7\% (World Breastfeeding Trends Initiative, 2020). According to the reports submitted in 2015, the rate of starting breastfeeding in the first 1 hour was $49 \%$, in Nigeria; the rate of exclusive breastfeeding in the first 6 months was 50\%; and the median duration of breastfeeding was 18.2 months. In the report from Tanzania, the rate of starting breastfeeding in the first 1 hour was $49 \%$, the rate of exclusive breastfeeding in the first 6 months was $50 \%$, the median duration of breastfeeding was 20 months, and the rate of bottle feeding before the end of first 6 months was 5\%. In the report from Uganda, the rate of starting breastfeeding in the first 1 hour was $52.5 \%$, the rate of exclusive breastfeeding in the first 6 months was $63.2 \%$, and the median breastfeeding period was 18 months. In the report from Gambia, the rate of exclusive breastfeeding in 
the first 6 months was $48 \%$, the rate of exclusive breastfeeding in the first 6 months was 20 months, and the rate of bottle feeding before the end of first 6 months was $7 \%$. In addition to the fact that there was no baby-friendly hospital initiation in Gambia, neither there were available updated materials, to help mothers who have problems with breastfeeding. In the report from Bosnia and Herzegovina; the rate of exclusive breastfeeding in the first 6 months was $18.5 \%$; and the rate of baby-friendly hospitals was $73 \%$. The baby-friendly hospital program started in 2009 and the baby nutrition policy was adopted in 2012. According to the 2015 report of Mexico, the rate of starting breastfeeding in the first 1 hour was $38 \%$, the rate of exclusive breastfeeding in the first 6 months was $14 \%$, and the rate of exclusive breastfeeding in the first 6 months was 14\%, and the median breastfeeding period was 10 months (World Breastfeeding Trends Initiative, 2020). According to the report submitted by Colombia, in 2017, the rate of starting breastfeeding in the first 1 hour was $57 \%$, the rate of exclusive breastfeeding in the first 6 months was $43 \%$, the median breastfeeding period was 15 months, and the rate of bottle feeding before the end of first 6 months was 55\% (World Breastfeeding Trends Initiative, 2020).

\section{Conclusion}

In conclusion, it is seen that the breastfeeding rates are far from the 2025 targets of the World Health Assembly, in TCCA countries. Especially, the use of bottle feeding is still very common and the rates of exclusive breastfeeding in the first 6 months are far from the desired targets. The first steps of raising healthier generations are to increase the rates of breastfeeding, the amount of breast milk, and immunization. The aim of this review is to underline the importance of exclusive use of breast milk for the first 6 months and continuing breastfeeding until 2 years of age with appropriate supplementary foods

Peer-review: Externally peer-reviewed.

Author Contributions: Concept- IGTİ BKT DesignIGTİ BKT; Supervision- IGTİ BKT; Funding-None Materials- IGTİ BKT.; Data Collection/Data ProcessIGTİ BKT; Analyze or Comment- IGTİ BKT.; Literature Scanning- IGTİ BKT; Writer of PaperIGTİ BKT.; Critical Review- IGTİ BKT

Conflict of Interest: No conflict of interest was declared by the authors.

Financial Disclosure: The authors declared that this study hasn't received no financial support.

\section{References}

Akyuz A, Kaya T, Senel N. Determination of Breastfeeding Behaviors of Mothers and Influencing Factors. TAF Preventive Medicine Bulletin 2007;6(5): 331-335.

Betrini G, Perugi S, Dani C, Pezzati M. Trochini M, Rubaltelli FF. Maternal education and the incidence and duration of breastfeeding: A prospective study. J Pediatr Gastroent Nutr 2003; 37: 447-52.

Bolat F, Uslu S, Bolat G, Bulbul A, Arslan S, Celik M, Nuhoglu A. The factors affecting breastfeeding in first 6 months. 2011; 11(1): 5-13.

Centers for Disease Control and Prevention. Breastfeeding report card-United States, published August 2012. (cited 2020 April 1) Available from: URL: http://www.cdc.gov/breastfeeding/ pdf/2012BreastfeedingReportCard.pdf.html.

Chierici R, Saccomandi D, Vigi V. Dietary Supplements for the Lactating mother: Influence on the Trace Element. Acta Paediatr Suppl. 1999; 88 (430): 7-13.

Gartner LM, Morton J, Lawrence RA, et al. American Academy of Pediatrics Section on Breastfeeding. Breasfeeding and the use of human milk. Pediatrics 2005; 115: 496-506 2.

Hoyer S, Pokorn D. The Influence of Various Factors on Breast-Feeding in Slovenia. J.Adv.Nurs. 1998;27 (6);1250-6.

Lancet, 2000. Effect of breastfeeding on infant and childhood mortality due to infectious diseases in less developed countries: a pooled analysis. WHO Collaborative Study Team on the Role of Breastfeeding on the Prevention of Infant Mortality. Lancet 2000; 355(9202): 451-5.

Liu P, Qiao L, Xu F, Zhang M, Wang Y, Binns CW. Factors associated with breastfeeding duration: A 30-month cohort study in northwest China. J. Hum. Lact. 2013; 29: 253-259.

Raister J. Midwifery Care Resarch: What Questions Are Being Asked? What Lessons Have Been Learned? J.Midwifery Womens Health. 2000; 45 (1): 20-36.

Samur G. Breast Milk.Ministry of Health Publications. Ankara; 2008.

Schmied V, Barclay L. Connection and Pleasure, Distruption and Distress: Women's Experiences of Breastfeeding, J. Hum.Lact. 1999;15(5):32534.

Turkey Demographic and Health Survey, 2018. Hacettepe University Institute of Population Studies. T.R. Presidency of Turkey Directorate of Strategy and Budget Ankara, Turkey. 2019. 
Turkish Cooperation and Coordination Agency. (cited 2020 January 7). Available from: URL: https://www.tika.gov.tr/en/page/about_us14650.html.

World Breastfeeding Trends Initiative. (cited 2020 January 7). Available from: URL: https://www.worldbreastfeedingtrends.org/p/what -is-wbti.html.

World Breastfeeding Trends Initiative. (cited 2020 January 10). Available from: URL: https://www.worldbreastfeedingtrends.org/upload s/country-data/countryreport/WBTi-Turkey2015.pdf.html.

World Breastfeeding Trends Initiative. (cited 2020 January 12). Available from: URL: https://www.worldbreastfeedingtrends.org/wbticountryreport.php?country_code=TR.html.

World Breastfeeding Trends Initiative. (cited 2020 January 13). Available from: URL: https://www.worldbreastfeedingtrends.org/wbticountry-report.php?country.html.

World Health Organization. (cited 2020 January 5). Available from: URL: https://www.who.int/newsroom/facts-in-pictures/detail/breastfeeding.html.

World Health Organization, 2014. Global Nutrition Targets 2025, Breastfeeding Policy Brief. (cited 2020 April 2). Available from: URL: https://apps.who.int/iris/bitstream/handle/10665/1 49022/WHO_NMH_NHD_14.7_eng.pdf?ua=1.ht $\mathrm{ml}$. 